\title{
A quality of life questionnaire for adolescents with cerebral palsy: psychometric properties of the Bengali CPQoL-teens
}

\author{
Rosalie Power ${ }^{1,2,7^{*}} \mathbb{D}$, Rahena Akhter ${ }^{3}$ (D), Mohammad Muhit ${ }^{2,4} \mathbb{D}$, Sabrina Wadud ${ }^{2,4}$, Eamin Heanoy ${ }^{2,4}$,
} Tasneem Karim ${ }^{1,2,4}$, Nadia Badawi ${ }^{1,5}$ and Gulam Khandaker ${ }^{1,2,4,6}$ (D)

\begin{abstract}
Background: Quality of life (QoL) and health-related quality of life (HRQOL) measurement in low and middleincome countries of people with cerebral palsy (CP), the major cause of childhood physical disability, is essential to assess the impact of interventions and inform policies that best improve people's lives. The purpose of this study was to cross-culturally translate and psychometrically validate the Cerebral Palsy Quality of Life-Teens (CPQoL-Teens) self- and proxy-report questionnaires for application with adolescents with CP in Bangladesh.

Method: The CPQoL-Teens questionnaires were translated to Bengali using forward and backwards cross-cultural translation protocols. The questionnaires were interviewer administered to adolescents and their primary caregivers, identified through the Bangladesh Cerebral Palsy Register. Feasibility, sensitivity, internal consistency, content, concurrent and construct validity were assessed.

Results: One hundred fifty four adolescents with CP (10 to 18y; mean 15y 1 mo SD 1y 8mo; $31.2 \%$ female) participated. Feasibility, sensitivity and internal consistency of both self- and proxy-report questionnaires was excellent; nil missing scores except 'school wellbeing' which was associated with non-school attendance (48.4 to 74.7\%); floor and ceiling effect $\leq 13.6 \%$; Cronbach's alpha 0.77 to 0.94 . Instrument validity was good; confirmatory factor analysis reflected five of the seven original instrument dimensions. CPQoL-Teens correlated to Kidscreen-27 on most dimensions ( $r=0.176$ to $0.693, p<0.05)$; minimal difference in known groups was observed by mental health status $(p<0.05)$ although could be accounted for by homogeneity of mental health problems in the sample.

Conclusion: The CPQoL-Teens self- and proxy report questionnaires successfully translated to Bengali and showed excellent feasibility and strong psychometric properties confirming suitability to assess indicators of HRQoL among adolescents with CP in Bangladesh.
\end{abstract}

Keywords: Cerebral palsy, Health-related quality of life, Bangladesh, Cerebral palsy quality of life teens, Disability, Adolescent, Psychometric properties, Validation

\footnotetext{
* Correspondence: rpow8982@uni.sydney.edu.au

${ }^{1}$ Discipline of Child and Adolescent Health, Faculty of Medicine and Health,

University of Sydney, Sydney, NSW, Australia

${ }^{2}$ Asian Institute of Disability and Development, University of South Asia,

Dhaka, Bangladesh

Full list of author information is available at the end of the article
}

(c) The Author(s). 2019 Open Access This article is distributed under the terms of the Creative Commons Attribution 4.0 International License (http://creativecommons.org/licenses/by/4.0/), which permits unrestricted use, distribution, and reproduction in any medium, provided you give appropriate credit to the original author(s) and the source, provide a link to the Creative Commons license, and indicate if changes were made. The Creative Commons Public Domain Dedication waiver (http://creativecommons.org/publicdomain/zero/1.0/) applies to the data made available in this article, unless otherwise stated. 


\section{Background}

Quality of life (QoL) and specifically health-related quality of life (HRQoL) assessment is becoming a fundamental component of public health surveillance. QoL is broadly defined as a subjective multidimensional concept for assessing a person's wellbeing across numerous life indicators [1]. HRQoL is a subset of QoL and used for measuring the interaction between health and indicators of wellbeing [2]. HRQoL is often overlooked in low and middle-income countries (LMICs) in part due to the complexities associated with its measurement however, can provide important understanding of the unique factors impacting people's lives allowing for focus on positives rather than on deficits (i.e. wellbeing rather than poverty) and contributing to sustainable development [3]. Moreover, HRQoL assessment can be used to deliver valid indicators of intervention outcomes (i.e. assess the impact of clinical interventions and treatment on quality of life as well as health service evaluation); provide understanding of burden of disease; and identification of priority areas for allocation of health resources, public health infrastructure development and policy guidance [4]. HRQoL assessment is particularly relevant to groups with long-term or chronic health conditions and/ or disability such as those with cerebral palsy $(\mathrm{CP})$ and those going through major transitions such as adolescents [5-7].

$\mathrm{CP}$ is the major cause of childhood physical disability worldwide and refers to a group of disorders affecting a person's ability to move or their posture caused by damage to the developing brain either during pregnancy or shortly after birth [8]. It can be associated with co-morbidities including intellectual disability, epilepsy, deafness, blindness and chronic pain among others [9]; and is often more common and more severe in LMICs [10, 11]. A recent population-based study from Bangladesh estimated the prevalence of CP to be 3.4 per 1000 children [12]. 68.2\% of the children were unable to walk and prevalence of associated impairments was also notably higher than international norms including visual, hearing impairments and epilepsy. Disability infrastructure and health services are sparse in Bangladesh although as a signatory to the United Nations Convention on the Rights of Persons with Disability and an adoptee of the Sustainable Development Goals, Bangladesh has made considerable efforts to respond to the voices of disability advocates and their allies and reduce inequality by focusing development on holistic concepts of wellbeing [13].

One of the most densely populated and under resourced countries in the world, Bangladesh has a large adolescent population constituting approximately one fifth of the total population. Adolescents in this context face unique circumstances; over $67 \%$ of adolescent girls are married and more than $50 \%$ will give birth before the age of $18[14,15]$. Adolescents with CP experience additional challenges as they negotiate their physical, emotional, social and sexual development whilst facing stigma related to their impairments (likely to be severe due to late diagnosis and lifelong lack of services and support $[12,13])$ and ostracism due to lack of perceived capacity to undertake narrowly defined adult roles such as being parents and income earners [16]. To date, international research has indicated that some adolescents with $\mathrm{CP}$, primarily from high-income countries (HICs), will experience similar wellbeing to their peers without disability [17] although those from LMICs are likely to lag behind their peers without disability and report extremely poor wellbeing [18]. Condition-specific instruments that study the relationship between $\mathrm{CP}$ and individual's subjective sense of wellbeing and that can be administered in low resource settings are necessary to understand and improve the lives of adolescents with $\mathrm{CP}$ $[19,20]$.

Cerebral Palsy Quality of Life Teens Questionnaire (CPQoL-Teens), an extension of the CPQoL-Child questionnaire, is a widely used condition specific instrument for studying the subjective wellbeing of adolescents with $\mathrm{CP}$ using a conceptual framework that aligns quality of life with wellbeing [21]. Originally developed in Australia (an HIC) using a grounded theory approach based on interviews with adolescents with $\mathrm{CP}$ and their primary caregivers [22], it is one of five known CP specific HRQoL measures although is the only instrument that is inclusive of indicators specific to adolescents with $\mathrm{CP}$ such as pain, participation, social isolation, and feelings about functioning [20]. To date, CPQoL-Teens has been translated to six other languages (Italian, Spanish, Cantonese, Mandarin, Japanese, Hebrew) although has not yet been applied in an LMIC. In the present study, we conducted a cross-cultural translation and adaptation of CPQoL-Teens and assessed the psychometric properties of the self- and proxy-report versions among adolescents with $\mathrm{CP}$ and their primary caregivers in Bangladesh.

\section{Method}

This study is part of the Bangladesh cerebral palsy healthrelated quality of life study (Bangladesh CP HRQoL) aimed at assessing the HRQoL of adolescents with CP in Bangladesh using a population-based sample. The present study reports the cross cultural translation and validation of the CPQoL-Teens questionnaire to determine feasibility, sensitivity, internal consistency, content, concurrent and construct validity for use in Bangladesh.

\section{Participants and study design}

Participants were identified through the Bangladesh Cerebral Palsy Register (BCPR), the first populationbased register of children and adolescents with $\mathrm{CP}$ in an LMIC [23]. BCPR is an ongoing surveillance program 
that has been operating since January 2015 and covers a defined geographical region, the Shahjadpur sub-district of Sirajganj district in the northern part of Bangladesh. The area includes 296 villages with a total combined population of 561,076 (child population approx. 226,114) and an estimated 70,998 households. Participants of BCPR are identified using Key Informant Methodology described in Khandaker, Smithers-Sheedy [23]. BCPR holds data on socio-demographic characteristics, clinical (including severity, aetiology, associated impairments and risk factors), nutrition, education and rehabilitation status of children and adolescents with $\mathrm{CP}$ in Bangladesh. We attempted to contact all adolescents aged 10 to $\leq 18$-years registered with BCPR at the time of this study to invite participation; ten to 18 is considered a normative classification of adolescence in Bangladesh [24]. Where possible we asked adolescents to self-report; we also requested proxy-reported data from their primary caregiver classified as a parent, grandparent, other relative or close adult friend who provided most of their care and support.

Informed consent was obtained from all individual participants included in the study. In cases of illiteracy, written consent was obtained by thumbprint from the primary caregiver. This study has ethical approval from the Bangladesh Medical Research Council (BMRC/ NREC/2013-2016/1165) and University of Sydney Human Research Ethics Committee (2016/646). All procedures performed in this study were in accordance with the ethical standards of these institutional and with the 1964 Helsinki declaration and its later amendments or comparable ethical standards.

\section{Measures}

Self- and proxy-reported (via primary caregivers) data were collected for all participants; adolescents were excluded from self-reporting in instances where they appeared unable to understand questions or communicate their answers. The questionnaires were interviewer-administered by trained workers. Each interview lasted approximately $45 \mathrm{~min}$.

\section{Cerebral palsy quality of life - teens (CPQoL-Teens)}

CPQoL-Teens is a CP condition specific survey-based instrument that measures subjective wellbeing in teenagers with $\mathrm{CP}$ using categorised statistical indicators, see Davis, Mackinnon [21] for the psychometric properties of the original Australian version. CPQoL-Teens has both self- and proxy-report options measuring seven dimensions; 'general wellbeing and participation' (21 items), 'communication and physical health' (16 items), 'school wellbeing' (8 items), 'social wellbeing' (7 items), 'access to services' (9 items, proxy report only), 'family health' ( 4 items, proxy report only) and 'feelings about functioning' (5 items). Participants are asked to rate their feelings on a nine-point Likert scale from 1, 'very unhappy' to 9 , 'very happy' by thinking about how they feel, rather than about what they can do. Each question commences with the phrasing "how do you feel about..." or "How do you think your teenager feels about...".

\section{Bengali version Kidscreen-27}

The Bengali version Kidscreen-27 was used to measure concurrent validity. Kidscreen-27 instrument is a generic population survey-based questionnaire that measures HRQoL of children and adolescents [25]. The instrument has self- and proxy-report versions to measure participant subjective perception of their wellbeing over the last week in relation to; 'physical wellbeing' (5 items), 'psychological wellbeing' (7 items), 'autonomy and parents' (7 items), 'peers and social support' (4 items), and 'school environment' (4 items). The Bengali version Kidscreen-27 reported strong psychometric properties for this study including good internal consistency (Cronbach's alpha self- and proxy-report 0.7 to 0.9 ) [26].

\section{Bengali version strengths and difficulties questionnaire (SDQ)}

The Bengali version Strengths and Difficulties Questionnaire (SDQ) was used to measure construct validity. SDQ provides an assessment on mental health including emotional symptoms (5 items), conduct problems (5 items), hyperactivity/ inattention (5 items), peer relationship problems ( 5 items), and pro-social behaviour (5 items) of children and adolescents. The Bengali version SDQ has previously been validated for use in Bangladesh [27].

\section{Bangladesh cerebral palsy register (BCPR)}

Demographic and disability related information were extracted from the BCPR database including age, sex, height, weight, gross motor function classification system (GMFCS) level, associated impairments, level of education and monthly family income [12].

\section{Cross-cultural translation and adaptation of CPQoL-teens}

Translation and adaptation of the self- and proxy-report questionnaires followed the CPQoL-Teens forwards and back translation protocol [28] with necessary socio-cultural adaptations to attain language, operational and scale equivalence $[29,30]$. The self- and proxy-report English versions were independently translated by two researchers fluent in both languages but for whom Bengali was their day-to-day language. The translators were given instruction to use natural and acceptable language for the broadest audience and to be simple, clear and concise in their formulations, as well as to focus on conceptual equivalence rather than literal word-for-word translation. The two translations were compared and 
assessed for conceptual equivalence, comprehensibility and clarity of speech relative to the original English questionnaires. A reconciled version of each questionnaire was produced as a derivative of the two translations.

The reconciled forward translation was back translated by a researcher fluent in both languages but for whom English was their day-to-day language. The same instructions for translation were given to the English translator. The back translation was then compared item-by-item with the original English questionnaires to develop the final forward translation document. Conceptual discrepancies between the translations were resolved, involving a researcher experienced in $\mathrm{CP}$, who analysed each item and chose the best translation, or suggested another translation if necessary. Pre-testing of the final self- and proxy-report questionnaires were undertaken with eight adolescents and primary caregivers to confirm the translations. Questions were discussed and reformulated by the researchers if understood by $<90 \%$ of participants, then tested with another group of eight adolescents with $\mathrm{CP}$ and primary caregivers. Acceptability of the instrument administration method, timeframe required for administration and use of the Likert scale were also assessed. This process was repeated until all items were understood by $>90 \%$ of participants. The translated questionnaires are available on request from CPQoL.

\section{Statistical analysis}

Data were checked for accuracy and records where age was invalid were excluded from analysis. CPQoL-Teens scores were converted to values between 0 and 100 , selected scores inverted so that higher scores indicated better HRQoL, and summary scores calculated by averaging the items with each dimension [28]. Dimension (average) scores were used for all subsequent analysis.

Feasibility was assessed as the proportion of missing values and was analysed by case-wise deletion. Instrument sensitivity was assessed using floor and ceiling effects, defined as the proportion of participants reporting the lowest and highest scores for each instrument dimension. Floor or ceiling effects $>15 \%$ were considered as high indicating that the instrument is not sensitive in the target population [25]. Internal consistency was calculated using Cronbach's $\alpha$. This coefficient has a value from 0 to 1 ; a value $\geq 0.7$ was considered to indicate high reliability of the instrument for use in group comparison and a value $\geq 0.9$ indicates high reliability for individual patient analysis [31, 32].

Content validity was assessed using confirmatory factor analysis (CFA) to confirm if the underlying dimensions of the translated questionnaire matched the original. Model fit was considered acceptable if the chisquare statistic was $p>0.05$ and root mean squared error of approximation (RMSEA) was $\leq 0.08$, comparative fit index (CFI) was $\geq 0.90$ and Tucker-Lewis Index (TLI) was $\geq 0.90$ [33]. Exploratory factor analysis (EFA) was undertaken if CFA was determined a poor model fit [34]. We conducted principal component analysis with Varimax rotation; factors were disregarded according to visual inspection of Scree plot and if eigenvalue was < 1.0. Forced extraction was conducted to achieve most interpretable solution [34].

Concurrent validity was assessed by determining the degree of correlation between related dimensions of CPQoLTeens and Kidscreen-27. Coefficients exceeding $r=0.7$ were considered satisfactory [35]. Construct validity was determined using the known group's method [2]. We assessed differences according presence of 'unlikely', 'possible' and 'probable' mental health problems using SDQ [25]. Magnitude of difference was determined by effect size as small $(\leq 0.49)$, medium ( 0.50 to 0.79$)$, and large $(\geq 0.80)$ (Cohen 1988). Concordance between self-report and proxy-report was assessed with intra class correlation (ICC) and comparison of group means. ICC $<0.4$ was considered to indicate poor to fair agreement, 0.50 to 0.69 moderate agreement, 0.70 to 0.79 good agreement, $>0.80$ excellent agreement [36]. All statistical analysis was conducted using SPSS version 24 (IBM Corporation, Chicago, Illinois, USA). A $p$ value of $<0.05$ was considered significant.

\section{Results}

\section{Participant characteristics}

One hundred ninety two adolescents with $\mathrm{CP}$ were registered in BCPR at the time of this study, of which 154 (mean age $15 \mathrm{y} 1 \mathrm{mo}$, SD $1 \mathrm{y} 8 \mathrm{mo}$, female $n=48,31.2 \%$ ) were enrolled to participate (participation rate $80.2 \%$ ). Reasons for non-participation included being unwilling to participate $(n=11,5.7 \%)$; no longer living in the surveillance area $(n=7,3.6 \%)$; not able to be retraced $(n=17$, $8.9 \%)$; and having deceased $(n=3,1.6 \%)$. Of the 154 adolescents with CP, 64 (41.56\%) provided self-reported data. Remainder were excluded from self-reporting due to severe communication and/ or cognitive impairment. Proxy-reported data was provided for all adolescents by primary caregivers; mothers $(n=118,76.62 \%)$, fathers $(n=21,13.64 \%)$ and other primary caregivers $(n=15$, 9.74\%), mean caregiver age 39y 9mo (SD 9y 9mo). Majority of adolescents with CP were underweight $(\mathrm{BMI}<18.5$ $n=107,69.48 \%)$ and did not attend school $(n=115$, 74.68\%). Participant GMFCS was Level I $n=36$ (23.38\%), Level II $n=23$ (14.94\%), level III $n=33(21.43 \%)$, level IV $n=20$ (12.99\%), level V $n=41$ (26.62\%). Median monthly family income was BDT 6000 (USD equiv. \$73).

\section{Feasibility}

Missing values, shown in Table 1, were nil for all dimensions except 'school wellbeing' (missing self-report 48.4\%; 
Table 1 Feasibility (missing scores), sensitivity (floor and ceiling effect) and internal consistency (Cronbach's a), of the Bengali version CPQoL-Teens

\begin{tabular}{|c|c|c|c|c|c|c|}
\hline \multirow[t]{2}{*}{ Instrument dimension } & \multirow[t]{2}{*}{ Items } & \multicolumn{5}{|c|}{ Adolescent with CP } \\
\hline & & $n$ & Missing scores $n(\%)$ & Floor effect $n(\%)$ & Ceiling effect $n(\%)$ & Cronbach's a \\
\hline \multicolumn{7}{|l|}{ Self-report } \\
\hline General wellbeing and participation & 21 & 64 & $0(0.0)$ & $0(0.0)$ & $0(0.0)$ & 0.92 \\
\hline Communication and physical health & 16 & 64 & $0(0.0)$ & $0(0.0)$ & $0(0.0)$ & 0.85 \\
\hline School wellbeing & 8 & 64 & $31(48.4)$ & $0(0.0)$ & $3(4.7)$ & 0.89 \\
\hline Social wellbeing & 7 & 64 & $0(0.0)$ & $0(0.0)$ & $2(3.1)$ & 0.77 \\
\hline Feelings about functioning & 5 & 64 & $0(0.0)$ & $1(1.6)$ & $2(3.1)$ & 0.87 \\
\hline \multicolumn{7}{|l|}{ Proxy-report } \\
\hline General wellbeing and participation & 21 & 154 & $0(0.0)$ & $0(0.0)$ & $0(0.0)$ & 0.94 \\
\hline Communication and physical health & 16 & 154 & $0(0.0)$ & $2(1.3)$ & $0(0.0)$ & 0.88 \\
\hline School wellbeing & 8 & 154 & 115(74.7) & $0(0.0)$ & $1(0.7)$ & 0.91 \\
\hline Social wellbeing & 7 & 154 & $O(0.0)$ & $2(1.3)$ & $1(0.7)$ & 0.82 \\
\hline Access to services & 9 & 154 & $0(0.0)$ & $1(0.7)$ & $2(1.3)$ & 0.88 \\
\hline Family health & 4 & 154 & $0(0.0)$ & $5(3.3)$ & $2(1.3)$ & 0.79 \\
\hline Feelings about functioning & 5 & 154 & $0(0.0)$ & 21(13.6) & $2(1.3)$ & 0.88 \\
\hline
\end{tabular}

proxy-report 74.7\%). Missing scores corresponded exactly to rates of non-school attendance.

\section{Sensitivity}

Floor and ceiling effects, Table 1, were observed as nil or weak on most dimensions for both self- and proxy-report questionnaires (0 to $4.7 \%$ ). Moderate ceiling effect was observed in proxy-report 'feelings about functioning' (13.6\%). No effects > 15\% were observed. Sub-group analysis by BMI, school attendance and monthly family income revealed no significant floor or ceiling effects confirming good sensitivity.

\section{Internal consistency}

Internal consistency, Table 1, was excellent; Cronbach's $\alpha$ self-report 0.77 to 0.92 and proxy-report 0.79 to 0.94 .

\section{Validity}

\section{Content validity}

CFA on the Bengali proxy-report questionnaire showed the original seven factor model was a poor fit (Chisquare $=5593.9, \quad \mathrm{df}=2326, \quad p<0.001, \quad \mathrm{RMSEA}=0.065$ (95\% CI 0.063 to 0.068$)$; $\mathrm{CFI}=0.612$; $\mathrm{TLI}=0.586)$. EFA was then conducted as sampling adequacy was acceptable (Bartlett $=<0.001, \mathrm{KMO}=0.858$ ). This resulted in a 15 factor solution with eigenvalues greater than one, explaining $75.7 \%$ of the variance. Forced factor extraction resulted in a final five-factor solution that explained $54.8 \%$ of the variance. This solution was most interpretable and corresponded, within one to three factors, with the original CPQoL-Teens dimensions, see Table 2. Final factor loadings for all factors ranged from 0.26 to 0.84 .
CFA was not conducted for the Bengali CPQoL-Teens self-report questionnaire due to insufficient sample size $(n=64)$.

\section{Concurrent validity}

Concurrent validity between CPQoL-Teens and Kidscreen-27 was good, as shown in Table 3. Significant moderate to strong correlation was observed in self-reported versions of the questionnaires on all dimensions ( $r=$ 0.257 to $0.693, p<0.05$ ) with two exceptions (CPQoLTeens 'social wellbeing' to Kidscreen-27 'peers \& social' and CPQoL-Teens 'feelings about functioning' to Kidscreen-27 'school wellbeing' $p>0.05$ ). Significant weak to strong correlations were observed in the proxy report version of the two questionnaires on all dimensions $(r=$ 0.173 to $0.648, p<0.05$ ) with ten exceptions (CPQoLTeens 'school wellbeing' to Kidscreen-27 'total score', 'psychological wellbeing,' 'autonomy and parents', and 'peers and social'; CPQoL-Teens 'social well-being' to Kidscreen-27 'school wellbeing'; CPQoL-Teens 'access to services' to Kidscreen-27 'psychological wellbeing', 'autonomy and parents' and 'school wellbeing'; and CPQoLTeens 'family health' to 'autonomy and parents' and 'school wellbeing', $p>0.05$ ).

\section{Construct validity}

The differences between 'known groups' according to SDQ mental health status ('unlikely', 'possible' or 'probable' mental health problem) are shown in Table 4. Group difference according to SDQ mental health status was observed in 'communication and physical health' and 'feelings about functioning' (mean difference 9.7 (0.6 
Table 2 Content Validity. CPQoL-Teens proxy-report item factor loadings

\begin{tabular}{|c|c|c|c|c|c|}
\hline & Factor 1 & Factor 2 & Factor 3 & Factor 4 & Factor 5 \\
\hline \multicolumn{6}{|l|}{ General wellbeing and participation } \\
\hline 1. their ability to participate in leisure and recreational activities? & 0.77 & & & & \\
\hline 2. their ability to participate in the community? & 0.77 & & & & \\
\hline 3. their ability to participate in social events outside of school? & 0.76 & & & & \\
\hline 4. having a go and trying new things? & 0.74 & & & -0.31 & \\
\hline 5. succeeding in things they want to be good at? & 0.72 & & & & \\
\hline 6. their positive attitude? & 0.71 & & & & \\
\hline 7. their ability to participate in sporting activities? & 0.70 & & & & \\
\hline 8. doing things they want to do? & 0.69 & & & & \\
\hline 9. their ability to get around in their neighbourhood? & 0.69 & & & & \\
\hline 10. themselves? & 0.69 & & & & \\
\hline 11. they way their are accepted by other teenagers outside of school? & 0.68 & & & & \\
\hline 12. their ability to get from place to place? & 0.66 & & 0.31 & & \\
\hline 13. hanging out with friends? & 0.65 & & & & \\
\hline 14. they way they get along with other teenagers outside of school (not school friends)? & 0.64 & & & & \\
\hline 15. their opportunities in life? & 0.64 & & & & \\
\hline 16. their future? & 0.58 & & & & \\
\hline 17. quality of life? & 0.56 & & & 0.43 & 0.33 \\
\hline 18. life as a whole? & 0.52 & & & 0.52 & 0.31 \\
\hline 19. the way they get around? & 0.52 & & & 0.32 & \\
\hline 20. life in general? & 0.48 & & & 0.45 & 0.33 \\
\hline 21. hanging out on their own? & 0.48 & & & 0.38 & \\
\hline \multicolumn{6}{|l|}{ Communication and physical health } \\
\hline 22. their ability to communicate with people they know well? & 0.75 & & & & \\
\hline 23. being able to do things by themselves without relying on others? & 0.72 & & & & \\
\hline 24. the way other people communicate with them? & 0.72 & & & & \\
\hline 25. the way they get along with adults? & 0.67 & & & -0.34 & \\
\hline 26. what they have achieved in their life? & 0.66 & & & & \\
\hline 27. their physical health? & 0.62 & & & 0.33 & \\
\hline 28. the way they are accepted by adults? & 0.62 & & & & \\
\hline 29. their plans for the future? & 0.59 & & & & \\
\hline 30. changes happening to their body to do with puberty? & 0.58 & & & & \\
\hline 31. their overall health? & 0.57 & & & 0.34 & \\
\hline 32. the way they are accepted by people in general? & 0.56 & 0.34 & & & \\
\hline 33. their ability to communicate with people they do not know well? & 0.56 & & & & \\
\hline 34. how they sleep? & 0.47 & & & & \\
\hline 35. what may happen to them later in life? & 0.44 & & & & \\
\hline 36. the way their communicate with people using technology (SMS, internet)? & 0.41 & & & & \\
\hline 37. their ability to keep up academically? & & 0.59 & & & \\
\hline \multicolumn{6}{|l|}{ School wellbeing } \\
\hline 38. the way they are treated the same as everyone as at school? & & 0.84 & & & \\
\hline 39. their ability to keep up physically? & & 0.77 & & & \\
\hline 40. their ability to participate at school? & & 0.77 & & & \\
\hline 41. the way they get along with their teachers at school? & & 0.75 & & & \\
\hline
\end{tabular}


Table 2 Content Validity. CPQoL-Teens proxy-report item factor loadings (Continued)

\begin{tabular}{|c|c|c|c|c|c|}
\hline & Factor 1 & Factor 2 & Factor 3 & Factor 4 & Factor 5 \\
\hline 42. the way they get along with other teenagers at school? & & 0.74 & & & \\
\hline 43. the way they are included by other students at school? & & 0.74 & & & \\
\hline 44. the way they are accepted by other students at school? & & 0.72 & & & \\
\hline 45. the way they are accepted by staff and teachers at school? & & 0.66 & & & \\
\hline \multicolumn{6}{|l|}{ Social wellbeing } \\
\hline 46. the way they get along with you (parents)? & 0.70 & & & & \\
\hline 47. the way they get along with people generally? & 0.62 & & & & \\
\hline 48. how happy they are? & 0.57 & & & 0.34 & 0.30 \\
\hline 49. going out on trips with the family? & 0.57 & & 0.38 & & \\
\hline 50. the way they get along with their brothers and sisters? & 0.55 & & & & \\
\hline 51. the support they get from their family? & 0.43 & & & -0.34 & 0.31 \\
\hline 52. the way they are accepted by their family? & 0.42 & & 0.33 & & \\
\hline \multicolumn{6}{|l|}{ Access to services } \\
\hline 53. your teenagers access to treatment? & 0.53 & 0.31 & -0.55 & & \\
\hline 54. your teenagers access to community services and facilities? & 0.49 & 0.34 & & & -0.34 \\
\hline 55. your teenagers access to speech therapy? & 0.45 & & -0.69 & & \\
\hline 56. ability to get advice from a paediatrician? & 0.45 & 0.35 & -0.63 & & \\
\hline 57. your teenagers access to specialised medical or surgical care? & 0.43 & 0.41 & -0.65 & & \\
\hline 58. your teenagers access to physiotherapy? & 0.43 & 0.34 & -0.69 & & \\
\hline 59. your teenagers access to occupational therapy? & 0.42 & 0.34 & -0.69 & & \\
\hline 60. your teenagers access to extra help with learning at school? & & 0.70 & & & \\
\hline 61. How much pain does your teenager have? & & & 0.26 & & \\
\hline \multicolumn{6}{|l|}{ Family health } \\
\hline 62. How happy are you? & 0.41 & & & & 0.45 \\
\hline 63. Your family's financial situation? & 0.41 & & & & 0.32 \\
\hline 64. Your work situation? & 0.31 & & -0.36 & & 0.57 \\
\hline 65. Your physical health? & & & -0.31 & & 0.54 \\
\hline \multicolumn{6}{|l|}{ Feelings about functioning } \\
\hline 66. their ability to dress him/herself? & 0.63 & & & & \\
\hline 67. their ability to eat or drink independently? & 0.60 & & & & \\
\hline 68. the way they use their arms and hands? & 0.59 & & & & \\
\hline 69. their ability to use the toilet by themself? & 0.58 & & & 0.33 & \\
\hline 70. the way they use their legs? & 0.44 & & & 0.46 & -0.31 \\
\hline Eigenvalue & 20.47 & 7.06 & 4.52 & 3.53 & 2.74 \\
\hline Percent variance & $29.25 \%$ & $10.08 \%$ & $6.46 \%$ & $5.05 \%$ & $3.91 \%$ \\
\hline
\end{tabular}

Extraction method: Principal component analysis; Rotation method: Varimax with Kaiser Normalization; Primary loadings are in bold

to 18.9$)$ to 17.8 (0.7 to 35.0$), \mathrm{ES}<0.4, p<0.05)$ although was insignificant for all other dimensions $(p>0.05)$. No difference was observed when analysed by socioeconomic status measured as monthly family income $(p>$ $0.05)$.

\section{Concordance between self- and proxy-report}

Concordance between self- and proxy-report, Table 5, was moderate to excellent for all dimensions (ICC 0.5 to
0.9). In all instances proxies estimated poorer HRQoL than adolescents themselves (mean difference 6.3 to 7.7 $p<0.05)$.

\section{Discussion}

To the best of our knowledge this is the first validation study of CPQoL-Teens in an LMIC using a populationbased sample of adolescents with CP. Our study demonstrated that the Bengali version CPQoL-Teens self- and 
Table 3 Concurrent validity. Spearman's correlation between CPQoL-Teens and Kidscreen-27 self- and proxy-reports

\begin{tabular}{|c|c|c|c|c|c|c|}
\hline \multirow[t]{2}{*}{ CPQoL-Teens } & \multicolumn{6}{|c|}{ Kidscreen-27 } \\
\hline & Total score & Physical wellbeing & Psych wellbeing & Autonomy parents & Peers social & School wellbeing \\
\hline \multicolumn{7}{|l|}{ Self-report } \\
\hline General wellbeing and participation & $.495^{* *}$ & $.556^{* *}$ & $.532^{* *}$ & $.390^{* *}$ & $.346^{* *}$ & $.460^{* *}$ \\
\hline Communication and physical health & $.505^{* *}$ & $.553^{* *}$ & $.459^{* *}$ & $.465^{* *}$ & $.370^{* *}$ & $.659^{* *}$ \\
\hline School wellbeing ${ }^{a}$ & $.693^{* *}$ & $.663^{* *}$ & $.458^{* *}$ & $.545^{* *}$ & $.490^{* *}$ & $.563^{* *}$ \\
\hline Social wellbeing & $.257^{*}$ & $.374^{* *}$ & $.378^{* *}$ & $.367^{* *}$ & .171 & $.377^{*}$ \\
\hline Feelings about functioning & $.485^{* *}$ & $.537^{* *}$ & $.598^{* *}$ & $.313^{*}$ & $.540^{* *}$ & .319 \\
\hline \multicolumn{7}{|l|}{ Proxy-report } \\
\hline General wellbeing and participation & $.648^{* *}$ & $.555^{* *}$ & $.568^{* *}$ & $.474^{* *}$ & $.544^{* *}$ & $.352^{*}$ \\
\hline Communication and physical health & $.603^{* *}$ & $.476^{* *}$ & $.513^{* *}$ & $.439^{* *}$ & $.555^{* *}$ & $.425^{* *}$ \\
\hline School wellbeing ${ }^{b}$ & .225 & $.365^{*}$ & .062 & .043 & .216 & $.327^{*}$ \\
\hline Social wellbeing & $.479^{* *}$ & $.389^{* *}$ & $.477^{* *}$ & $.366^{* *}$ & $.357^{* *}$ & .054 \\
\hline Feelings about functioning & $.529^{* *}$ & $.598^{* *}$ & $.447^{* *}$ & $.295^{* *}$ & $.467^{* *}$ & $.391^{*}$ \\
\hline Access to services & $.226^{* *}$ & $.171^{*}$ & .137 & .099 & $.173^{*}$ & .106 \\
\hline Family health & $.269^{* *}$ & $.257^{* *}$ & $.391^{* *}$ & .120 & $.243^{* *}$ & .082 \\
\hline
\end{tabular}

** correlation is significant at 0.01 level; * correlation is significant at the 0.05 level

${ }^{\mathrm{a}} n=33 ;^{\mathrm{b}} n=39$

proxy-report questionnaires have overall good psychometric properties and are reliable and valid measures to assess indicators of HRQoL among adolescents with CP in Bangladesh. We followed a rigorous cross-cultural translation and adaptation procedure; we used multistage forward and back translation with pilot testing to attain appropriate language and socio-cultural adaptations and adjusted instrument administration (questionnaires were interviewer administered) to account for low levels of literacy within our target population [12]. Acceptability of instrument administration method, timeframe and use of Likert scale measurement were confirmed during pilot testing.

The Bengali version CPQoL-Teens self- and proxy-report questionnaires produced psychometric properties comparable to the original Australian versions, with minor variations [21]. Missing scores were $<5 \%$ in the Australian version (for sub-dimensions included in the final questionnaire). Our study reported nil missing scores except in 'school wellbeing' (due to non-school attendance in the sample rather than an administration issue, discussed shortly). The Australian versions reported no floor effects; ceiling effects were $1-7 \%$. The Bengali versions study reported weak floor and ceiling effects (range 0 to $4.7 \%$ ) with the exception of a moderate floor effect in the proxy version 'feelings about functioning'. This dimension should be monitored in future applications of CPQoL-Teens although is a likely reflection of the lifelong lack of therapy and treatment options and subsequent severity of impairment among children with $\mathrm{CP}$ in Bangladesh [12]. Regarding internal consistency, Cronbach's $\alpha$ in the Australian CPQoL-

Table 4 Known group differences. Mean difference in CPQoL-Teens proxy-reported scores according to mental health status (SDQ)

\begin{tabular}{|c|c|c|c|c|}
\hline Instrument dimension & $\begin{array}{l}\text { SDQ 'unlikely' to 'possible' mean } \\
\text { difference ( } 95 \% \text { Cl) }\end{array}$ & $\begin{array}{l}\text { SDQ 'unlikely' to 'probable' mean } \\
\text { difference ( } 95 \% \mathrm{Cl})\end{array}$ & $\begin{array}{l}\text { SDQ 'possible' to 'probable' mean } \\
\text { difference }(95 \% \mathrm{CI})\end{array}$ & $\begin{array}{l}\text { Effect } \\
\text { size (ES) }\end{array}$ \\
\hline $\begin{array}{l}\text { General wellbeing and } \\
\text { participation }\end{array}$ & $11.3(-2.1$ to 24.7$)$ & $9.1(-1.9$ to 20.2$)$ & $2.2(-8.3$ to 12.6$)$ & 0.03 \\
\hline $\begin{array}{l}\text { Communication and } \\
\text { physical health }\end{array}$ & $13.4^{*}(2.2$ to 24.5$)$ & $9.7^{*}$ (0.6 to 18.9 ) & $3.6(-5.0$ to 12.3$)$ & 0.06 \\
\hline School wellbeing ${ }^{\text {a }}$ & $8.8(-16.2$ to 33.7$)$ & $1.1(-16.0$ to 18.3$)$ & $7.6(-14.8$ to 30.0$)$ & 0.02 \\
\hline Social wellbeing & $11.7(-0.7$ to 24.1$)$ & $8.1(-2.2$ to 18.3$)$ & $3.7(-6.0$ to 13.3$)$ & 0.03 \\
\hline Access to services & $2.1(-13.8$ to 18.1$)$ & 4.5 (-8.7 to 17.6$)$ & $6.6(-5.8$ to 19.0$)$ & 0.01 \\
\hline Family health & 8.6 (-6.1 to 23.2$)$ & $9.2(-2.9$ to 21.3$)$ & $0.6(-10.8$ to 12.0$)$ & 0.02 \\
\hline $\begin{array}{l}\text { Feelings about } \\
\text { functioning }\end{array}$ & $17.8^{*}(0.7$ to 35.0$)$ & 7.6 (-6.6 to 21.7) & $10.3(-3.1$ to 23.6$)$ & 0.04 \\
\hline
\end{tabular}

* significant at the 0.05 level

a $n=39$ 
Table 5 Concordance between self- and proxy-reports. ICC and mean difference between self- and proxy-reported CPQoL-Teens $(n=64)$

\begin{tabular}{|c|c|c|c|}
\hline Instrument Dimension & ICC (95\% Cl) & Mean difference $(95 \% \mathrm{Cl})$ & $p$-value \\
\hline General wellbeing and participation & $0.8(0.7$ to 0.9$)$ & 6.5 (3.3 to 9.6$)$ & $<0.0001^{b}$ \\
\hline Communication and physical health & 0.8 (0.6 to 0.9 ) & 6.7 (3.6 to 9.7 ) & $<0.0001^{b}$ \\
\hline School wellbeing ${ }^{\text {a }}$ & 0.9 (0.7 to 0.9$)$ & 7.7 (4.2 to 11.3$)$ & $<0.0001^{\mathrm{b}}$ \\
\hline Social wellbeing & 0.5 (0.2 to 0.7$)$ & 7.0 (3.1 to 10.9$)$ & $0.001^{c}$ \\
\hline Feelings about functioning & 0.7 (0.4 to 0.8$)$ & $6.3(0.2$ to 12.4$)$ & $0.021^{c}$ \\
\hline
\end{tabular}

${ }^{\mathrm{a}} n=33 ;{ }^{\mathrm{b}}$ paired samples $t$-test; ${ }^{\mathrm{C}}$ Wilcoxon signed rank test

Teens was 0.78 to 0.96 self-report and 0.81 to 0.96 proxy-report. Internal consistency was similarly excellent in the Bengali versions exceeding scale cut offs for group comparison (Cronbach's $\alpha<0.70$ ), although further testing is recommended before use in individual patient analysis as most dimensions were Cronbach's $\alpha<0.90$.

Adolescents with CP in our sample reported high rates of mental health problems (19.5\% 'possible' and 63.6\% 'probable') although this is similar to prevalence of mental health problems amongst children and adolescents with CP reported elsewhere [37]; and all participants lived in a rural area of Bangladesh and had similar levels of monthly family income. The Bengali version CPQoLTeens did not discriminate well between groups on the basis of these characteristics however this is likely due to homogeneity in our sample. Previous studies that have used these characteristics to test known group difference have conducted assessment with more sensitive measures including the 'Family Affluence Scale' (FAS) however use of FAS was not feasible in our low-resource setting $[38,39]$. Administration of CPQoL-Teens amongst adolescents with $\mathrm{CP}$ in other geographic regions of Bangladesh is recommended to further testing to known group difference.

We identified a high proportion of missing data in 'school wellbeing' associated with non-school attendance, which is common for adolescents with disability in Bangladesh [40]. These findings indicated that the Bengali translated CPQoL-Teens may address indicators of HRQoL that are not universally applicable for adolescents with CP in Bangladesh. Supplementary dimensions may be required for the Bangladeshi context, for example, to capture QoL data about non-school attendance for Bangladeshi adolescents with CP. This is an area for future research.

Concurrent validity examined agreement between subdimensions in the Bengali CPQoL-Teens and Bengali Kidscreen-27. Moderate to strong correlation was observed between most but not all sub-dimensions. Lack of correlation is suggested to be the result of conceptual differences in the instruments. Kidscreen-27 focuses on activities (e.g. "Thinking about the last week, have you ...) whereas CPQoL-Teens focus on feelings (e.g. "How do you feel about...").
Self-report is the gold standard of QoL assessment although exclusive use of proxy-reported data is common in HRQoL studies in LMICs [18]. We anticipated due to high prevalence of severe communication and/ or cognitive impairment that numerous adolescents would not be able to self-report however we ensured that in all instances data were collected directly from the adolescent as well as from their primary caregiver; this was possible in $41.6 \%$ of cases. To understand the agreement between self- and proxy-report we conducted case-wise comparison. Dimensions with observable components, for example, 'general wellbeing and participation' showed stronger agreement and dimensions with non-observable emotional components, for example 'social wellbeing' showed weaker agreement. Further discussion on the pattern of self- vs proxy-reported scores is provided in Power, Muhit [41]. Our findings of discordance were consistent with other research [42, 43] and provide strong argument for research design to include methods that enable collection of self-reported data.

Measure of HRQoL is widely adopted in HICs and majority of HRQoL instruments originate from these settings [44], as was the case with CPQoL-Teens. Crosscultural translation and adaptation of HRQoL instruments can be complex, lacking local context, however are useful from a public health perspective to identify international trends and enable collaboration [3, 29]. Moreover, argument can be made that although context will vary between HICs and LMICs, people with disability share similar social positions (i.e. in regards to marginalisation and oppression) providing a point of unity when conducting cross-cultural HRQoL assessment [7, 45]. Determining how HRQoL is conceptualised amongst our target population and providing commentary on the theoretical developments of 'wellness' was beyond our scope; although analysis of instrument dimensions confirmed that CPQoL-Teens reflected internationally defined multidimensional theoretical constructs of HRQoL [2, 3]. Moreover, assessment of content validity on the proxy-report questionnaire reflected five of the seven dimensions of the originals CPQoL-Teens although further testing with larger samples is required to confirm the factor structure. 


\section{Limitations}

A limitation of this study is that the questionnaires were originally developed in high-income (western) countries for use with children/ adolescents of defined ages, which differed to our age classification of adolescence in Bangladesh. Specifically CPQoL-Teens was originally developed for use with 13 to 18 year olds, SDQ for use with 3 to 16 year olds, and Kidscreen-27 for use with 8 to 18 year olds. This study considered adolescents in Bangladesh as 10 to 18 years, noted previously; meaning the instruments were applied outside of the age range for which they were originally developed and validated.

A further limitation of this study is that due to resource constraints we do not measure test-retest reliability or structural validity however we provide a thorough analysis of feasibility, sensitivity, internal consistency, content, concurrent and construct validity. Further testing of both questionnaires with samples from different geographical regions of Bangladesh would complement our findings.

\section{Conclusion}

CPQoL-Teens self- and proxy-report questionnaires underwent rigorous procedure for cross-cultural translation and adaptation and reported strong psychometric properties indicating suitability for use assessing the HRQoL of adolescents with CP in an LMIC, Bangladesh. The Bengali version CPQoL-Teens questionnaires were sensitive for adolescents with CP and captured information specific to this cohort, although relevance of 'school wellbeing' requires further investigation due to high levels of non-school attendance within our surveillance area. The questionnaires indicated good internal consistency for use in group comparison. Psychometric validation of CPQoL-Teens for use in Bangladesh is an important development to enable holistic assessment of adolescent's wellbeing in an LMICs and guide disability infrastructure development and policies.

\section{Abbreviations}

CP: Cerebral palsy; CPQoL-Teens: Cerebral Palsy Quality of Life Teens Questionnaire; ES: Effect size; GMFCS: Gross motor function classification system; HICs: High-income countries; HRQoL: Health-related quality of life; LMICs: Low and middle-income countries; SD: Standard deviation

\section{Acknowledgements \\ We acknowledge the CSF Global team in Bangladesh for their cordial support in implementing this project and supporting the families of children with CP in referrals and access to services. We thank the CPQoL team at the University of Melbourne, Australia, for permission to use the Cerebral Palsy Quality of Life Questionnaire.}

\section{Authors' contributions}

This study was conceived and designed by GK, MM, RP. SW, EH, TK and GK, made substantial contributions to the acquisition of data. RP, SW, EH, TK, GK, $\mathrm{RA}, \mathrm{NB}$, and MM made substantial contribution to the analysis and interpretation of data. RP wrote the first draft and SW, EH, TK, GK, RA, NB, and $\mathrm{MM}$ critically reviewed the manuscript and provided important intellectual content. All authors approved the final manuscript for publication. Interviews were undertaken by SW, EH, TK, GK. RP conducted the statistical analysis with input from GK and RA. RP wrote the first draft. All authors reviewed all drafts and approved the final submitted manuscript.

\section{Funding}

This study has been supported by the Cerebral Palsy Alliance Research Institute Australia Project Grant (PG3615). RP is supported by the Cerebral Palsy Alliance Research Institute Australia Career Development Grant (CDG04117). The study sponsor played no role in study design; collection, analysis, and interpretation of data; writing of the report; and in the decision to submit the paper for publication.

\section{Availability of data and materials}

The datasets used and/or analysed during the current study are available from the corresponding author on reasonable request.

\section{Ethics approval and consent to participate}

Informed consent was obtained from all individual participants included in the study. In cases of illiteracy, written consent was obtained by thumbprint from the primary caregiver. This study has ethical approval from the Bangladesh Medical Research Council (BMRC/NREC/2013-2016/1165) and University of Sydney Human Research Ethics Committee (2016/646). All procedures performed in this study were in accordance with the ethical standards of these institutional and with the 1964 Helsinki declaration and its later amendments or comparable ethical standards.

\section{Consent for publication}

Not applicable.

\section{Competing interests}

The authors declare that they have no competing interests.

\section{Author details}

'Discipline of Child and Adolescent Health, Faculty of Medicine and Health, University of Sydney, Sydney, NSW, Australia. ${ }^{2}$ Asian Institute of Disability and Development, University of South Asia, Dhaka, Bangladesh. ${ }^{3}$ School of Dentistry, Faculty of Medicine and Health, University of Sydney, Sydney, NSW, Australia. ${ }^{4}$ CSF Global, Dhaka, Bangladesh. ${ }^{5}$ Cerebral Palsy Alliance Research Institute, University of Sydney, Sydney, NSW, Australia. ${ }^{6}$ Central Queensland Public Health Unit, Central Queensland Hospital and Health Service, QLD, Rockhampton, Australia. ${ }^{7} T$ The Children's Hospital at Westmead Clinical School, Cnr Hawkesbury Rd and Hainsworth St, Locked Bag 4001, Westmead, NSW 2145, Australia.

Received: 26 August 2018 Accepted: 30 July 2019

Published online: 02 August 2019

References

1. The WHOQoL Group. The World Health Organization quality of life assessment (WHOQoL) development and psychometric properties. Soc Sci Med. 1998;46:1569-85.

2. Matza LS, Swensen AR, Flood EM, Secnik K, Leidy NK. Assessment of healthrelated quality of life in children: a review of conceptual, methodological, and regulatory issues. Value Health. 2004;7(1):79-92.

3. Camfield L. Quality of life in developing countries. In: Land K, Sirgy M, Michalos A, editors. Handbook of social indicators and quality of life research: Springer Science+Business Media; 2012.

4. Bjornson KF, McLaughlin JF. The measurement of health-related quality of life (HRQL) in children with cerebral palsy. Eur J Neurol. 2001;8(Suppl 5):183-93.

5. Gilson KM, Davis E, Reddihough D, Graham K, Waters E. Quality of life in children with cerebral palsy: implications for practice. J Child Neurol. 2014; 29(8):1134-40

6. Spieth LE, Harris CV. Assessment of health-related quality of life in children and adolescents: an integrative review. J Pediatr Psychol. 1996;21(2):175-93.

7. Oles M. Dimensions of identity and subjective quality of life in adolescents. Soc Indic Res. 2016;126(3):1401-19.

8. Rosenbaum P, Paneth N, Leviton A, Goldstein M, Bax M. A report: the definition and classification of cerebral palsy. Dev Med Child Neurol. 2006; 109:8-14. 
9. Novak I, Hines M, Goldsmith S, Barclay R. Clinical prognostic messages from a systematic review on cerebral palsy. Pediatrics. 2012;130(5):1-28.

10. Cruz M, Jenkins R, Silberberg D. The burden of brain disorders. Science. 2006;312(5770):53.

11. Oskoui M, Coutinho F, Dykeman J, Jette N, Pringsheim T. An update on the prevalence of cerebral palsy: a systematic review and meta-analysis. Dev Med Child Neurol. 2013;55(1):509-19.

12. Khandaker G, Muhit M, Karim T, Smithers-Sheedy H, Novak I, Jones C, et al. Epidemiology of cerebral palsy in Bangladesh: a population-based surveillance study. Dev Med Child Neurol. 2019;61(5):601-9.

13. UNICEF. Situational analysis on children with disabilities in Bangladesh. Bangladesh; 2014.

14. National Institute of Population Research and Training (NIPORT), Associates Ma, International I. Bangladesh Demographic and Health Survey 2014. Dhaka, Bangladesh; 2016

15. Amin S, Ainul S, Akter F, Alam M, Hossain M, Ahmed J, et al. From evidence to action: results from the 2013 baseline survey for the BALIKA project. New York; 2014.

16. Hosain GM, Atkinson D, Underwood P. Impact of disability on quality of life of rural disabled people in Bangladesh. J Health Popul Nutr. 2002;20(4):297-305.

17. Clover A, Rapp M, Eisemann N, Ehlinger V, Thyen U, oDickinson H, et al. Selfreported quality of life of adolescents with cerebral palsy: a cross-sectional and longitudinal analysis. Lancet. 2015;385(1):705-16.

18. Power R, King C, Muhit M, Heanoy E, Galea C, Jones C, et al. Health-related quality of life of children and adolescents with cerebral palsy in low- and middle-income countries: a systematic review. Dev Med Child Neurol. 2018; 60(5):469-79.

19. Wiebe S, Guyatt G, Weaver B, Matijevic S, Sidwell C. Comparative responsiveness of generic and specific quality-of-life instruments. J Clin Epidemiol. 2003;56(1):52-60.

20. Carlon S, Shields N, Yong K, Gilmore R, Sakzewski L, Boyd R. A systematic review of the psychometric properties of quality of life measures for school aged children with cerebral palsy. BMC Pediatr. 2010;10(81):81.

21. Davis E, Mackinnon A, Davern M, Boyd R, Bohanna I, Waters E, et al. Description and psychometric properties of the CP QOL-teen: a quality of life questionnaire for adolescents with cerebral palsy. Res Dev Disabil. 2013; 34(1):344-52.

22. Davis E, Shelly A, Waters E, Mackinnon A, Reddihough D, Boyd R, et al. Quality of life of adolescents with cerebral palsy: perspectives of adolescents and parents. Dev Med Child Neurol. 2009:51(3):193-9.

23. Khandaker G, Smithers-Sheedy H, Islam J, Alam M, Jung J, Novak I, et al. Bangladesh cerebral palsy register (BCPR): a pilot study to develop a national cerebral palsy (CP) register with surveillance of children for CP. BMC Neurol. 2015:15:173.

24. Sigma A, Bajracharya A, Reichenbach L, Gilles K. Adolescents in Bangladesh: a situation analysis of programmatic approaches to sexual and reproductive health education and services. Washington, DC \& Dhaka, Bangladesh; 2017.

25. Ravens-Sieberer U, Herdman M, Devine J, Otto C, Bullinger M, Rose M, et al. The European KIDSCREEN approach to measure quality of life and wellbeing in children: development, current application, and future advances. Qual Life Res. 2014;23(3):791-803.

26. Power R, Akhter R, Muhit M, Wadud S, Heanoy E, Karim T, et al. Crosscultural validation of the Bengali version KIDSCREEN-27 quality of life questionnaire. BMC Pediatr. 2019;19(1):19.

27. Mullick MS, Goodman R. Questionnaire screening for mental health problems in Bangladeshi children: a preliminary study. Soc Psychiatry Psychiatr Epidemiol. 2001;36(2):94-9.

28. Davis E, Davern M, Waters E, Boyd R, Reddihough D, Mackinnon A, et al. Cerebral palsy quality of life questionnaire for adolescents (CP QOL-teen) manual. Melbourne: University of Melbourne; 2013.

29. Bullinger $M$, Anderson R, Cella D, Aaronson N. Developing and evaluating cross-cultural instruments from minimum requirements to optimal models. Qual Life Res. 1993;2(6):451-9.

30. Acquadro C, Conway K, Hareendran A, Aaronson N. European regulatory issues and quality of life assessment (ERIQA) group. Literature review of methods to translate health-related quality of life questionnaires for use in multinational clinical trials. Value Health. 2008;11(3):509-21.

31. Hays RD, Anderson R, Revicki D. Psychometric considerations in evaluating health-related quality of life measures. Qual Life Res. 1993;2(6):441-9.

32. Cronbach L. Coefficient alpha and the internal structure of the tests. Psychometrika. 1951;16:297-334.
33. Hu L, Bentler P. Cutoff criteria for fit indexes in covariance structure analysis: conventional criteria versus new alternatives. Struct Equ Model. 1999;6(1):155

34. Zwick R, Velicer W. Comparison of five rules of determining the number of components to retain. Psychol Bull. 1986;9:432-42.

35. Terwee CB, Bot SD, de Boer MR, van der Windt DA, Knol DL, Dekker J, et al. Quality criteria were proposed for measurement properties of health status questionnaires. J Clin Epidemiol. 2007;60(1):34-42.

36. Bartko JJ. The intraclass correlation coefficient as a measure of reliability Psychol Rep. 1966;19(1):3-11.

37. Downs J, Blackmore AM, Epstein A, Skoss R, Langdon K, Jacoby P, et al. The prevalence of mental health disorders and symptoms in children and adolescents with cerebral palsy: a systematic review and meta-analysis. Dev Med Child Neurol. 2018;60(1):30-8.

38. Ravens-Sieberer U, Auquier P, Erhart M, Gosch A, Rajmil L, Bruil J, et al. The KIDSCREEN-27 quality of life measure for children and adolescents: psychometric results from a cross-cultural survey in 13 European countries. Qual Life Res. 2007;16(8):1347-56.

39. von Rueden U, Gosch A, Rajmil L, Bisegger C, Ravens-Sieberer U. Socioeconomic determinants of health related quality of life in childhood and adolescence: results from a European study. J Epidemiol Community Health. 2006:60(2):130-5.

40. Centre for Services and Information on Disability. Educating children in difficult circumstances: children with disabilities. Bangladesh: Government of the People's Republic of Bangladesh Department for International Development; 2002

41. Power R, Muhit M, Heanoy E, Karim T, Badawi N, Akhter A, et al. Healthrelated quality of life of adolescents with cerebral palsy in rural Bangladesh. PLOS One. 2019;14(6);e0217675.

42. White-Koning M, Arnaud C, Dickinson HO, Thyen U, Beckung E, Fauconnier $J$, et al. Determinants of child-parent agreement in quality-of-life reports: a European study of children with cerebral palsy. Pediatrics. 2007;120(4):e80414.

43. Martin-Herz S, Bjornson K, Belza B, Kartin D, Logsdon R, McLaughlin J. Agreement between parent-proxy and adolescents self-rating of quality of life in adolescents with cerebral palsy. Dev Med Child Neurol. 2011;53:55.

44. Livingston MH, Rosenbaum PL, Russell DJ, Palisano RJ. Quality of life among adolescents with cerebral palsy: what does the literature tell us? Dev Med Child Neurol. 2007:49(3):225-31.

45. Putnam M. Conceptualizing Disability. Journal of Disability Policy Studies. 2005:16(3):188-98

\section{Publisher's Note}

Springer Nature remains neutral with regard to jurisdictional claims in published maps and institutional affiliations.

Ready to submit your research? Choose BMC and benefit from:

- fast, convenient online submission

- thorough peer review by experienced researchers in your field

- rapid publication on acceptance

- support for research data, including large and complex data types

- gold Open Access which fosters wider collaboration and increased citations

- maximum visibility for your research: over $100 \mathrm{M}$ website views per year

At $\mathrm{BMC}$, research is always in progress.

Learn more biomedcentral.com/submissions 